\title{
PTEN/MMAC1 enhances the growth inhibition by anticancer drugs with downregulation of IGF-II expression in gastric cancer cells
}

\author{
Pyoung Han Hwang ${ }^{1,2}$, Sun Young Kim², \\ Jung Chang Lee ${ }^{2}$, Sun Jun Kim ${ }^{1,2}$, \\ Ho Keun $\mathrm{Yi}^{3}$ and Dae-Yeol Lee ${ }^{1,2,4}$ \\ 'Department of Pediatrics \\ ${ }^{2}$ Research Institute of Clinical Medicine \\ School of Medicine \\ 'Department of Biochemistry \\ School of Dentistry \\ Chonbuk National University \\ Jeonju, Jeonbuk 561-712, Korea \\ ${ }^{4}$ Corresponding author: Tel, 82-63-250-1469; \\ Fax, 82-63-250-1464; E-mail, leedy@moak.chonbuk.ac.kr
}

\section{Accepted 5 August 2005}

Abbreviation: IGF, insulin-like growth factor; IGF-IR, insulin-like growth factor-1 receptor, MTT, 3-(4,5-dimethylthiazol-2-yl)-2, 5-diphinyltetrazolium bromide; PI3-kinase, phosphatidylinositol 3-kinase; RT$P C R$, reverse transcription-PCR

\begin{abstract}
PTEN/MMAC1 is a tumor suppressor gene that is mutated in a variety of advanced and metastatic cancers. Its major function is likely to be the phosphatase activity that regulates the phosphotidylinositol (PI)3-kinase/ Akt pathway. On the other hand, IGF system plays an important role in cell proliferation and cell survival via PI3-kinase/Akt and mitogen-activated protein kinase pathways in many cancer cells. To evaluate effect of PTEN on cell growth and IGF system in gastric cancer, human gastric adenocarcinoma cells (SNU-5 \& -216) were transfected with human PTEN cDNA. Those PTENtransfected gastric cancer cells had a lower proliferation rate than the pcDNA3-transfected cells. PTEN overexpression induced a profound decrease in the IGF-II and IGF-IR expression levels, and downregulation of IGF-II expression by PTEN was mediated through the regulation of the IGF-II promoter. In addition, a PI3-kinase inhibitor, LY294002, induced the downregulation of IGF-II expression. The PTEN-overexpressing SUN-5 and $\mathbf{- 2 1 6}$ cells were more sensitive to death induced by etoposide and adriamycin that induce DNA damage than the
\end{abstract}

pcDNA3-transfected cells. These findings suggest that PTEN suppresses the cell growth through modulation of IGF system and sensitizing cancer cells to cell death by anticancer drugs.

Keywords: genes, tumor supprressor; insulin-like growth factor II; receptor, IGF type I; stomach neoplasms

\section{Introduction}

There is a high frequency of mutations in the tumor suppressor gene encoding PTEN in many primary human cancers and several familial cancer predisposition disorders (Liaw et al., 1997; Teng et al., 1997; Steck et al., 1999). PTEN contains a sequence motif that is highly conserved in members of the protein tyrosine phosphatase family (Furnari et al., 1997; Maehama et al., 1998). Many cancerrelated mutations have been mapped within the conserved catalytic domain of PTEN, suggesting that the phosphatase activity of PTEN is essential for the tumor suppressor function. In addition, wild-type PTEN, but not the mutant derivatives lacking phosphatase activity, suppresses the growth of glioblastoma cells and their tumorigenecity (Li et al., 1988), which confirms the functional relevance of the PTEN phosphatase domain for tumor suppression.

Insulin-like growth factor (IGF)-I and -II are potent mitogens in many cell types in autocrine, paracrine and endocrine pathways (Daughaday et al., 1989). The biological effects of IGFs are specifically mediated by binding to the cell-surface IGF-I receptor (IGF-IR) and activating the receptor tyrosine kinase (LeRoith et al., 1995). Many tumors including gastric cancer overexpress IGF-II, IGF-IR and specific IGFBPs (Macualay, 1992; Yi et al., 2001). IGF-II expression results in an autocrine feedback loop activating IGF-IR and stimulating cancer cell proliferation (Chen et al., 1998; Sung et al., 2003).

An Akt pathway, which is known to induce cellular transformation, is activated by the growth factors involved in angiogenesis and metastasis, such as platelet-derived growth factor, epidermal growth factor, and insulin-like growth factor-I (Hemmings, 1997). Recent studies have shown that, PTEN inhibits the downstream function mediated by the phosphatidylinositol 3 (PI3)-kinase/Akt pathway, such as activation of protein kinase $B$ (PKB, also known as Akt), 
cell survival and cell proliferation, presumably through dephosphorylation of phosphatidylinositol 3,4, 5 -triphosphate in vitro (Maehama et al., 1998). There are some evidences suggesting a possible connection between PTEN and the IGF system (Davies et al., 1998; Stambolic et al., 1998). Since IGF promotes cell proliferation and cell survival through the PI3 kinase pathway, PTEN can directly modulate the IGF-induced activation of $\mathrm{PI} 3$ kinase, thereby inhibiting the IGF-Induced cell proliferation. Recently, Zhao et al., (2004) have reported that PTEN inhibits cell proliferation and induces apoptosis by downregulating IGF-IR expression.

This study has found that PTEN inhibits the cell growth of gastric cancer cells with the downregulation of IGF-II and IGF-IR expression. In addition, PTEN overexpression results in the increased sensitivity of tumor cells to anticancer drugs.

\section{Materials and Methods}

\section{Materials}

The cell culture media (RPMI-1640) were purchased from Life Technologies Inc (Grand island, NY). The etoposide, adriamycin, and LY294002 were purchased from Sigma (St. Louis, MO). Polyclonal antiIGF-IR and monoclonal anti-PTEN antibodies, and all secondary antibodies were purchased from Santa Cruz Biotechnology (Santa Cruz, CA).

\section{Cell lines and cell culture}

Two established human gastric adenocarcinoma cell lines from Korean (SNU-5 and-216) were purchased from the Korea Cell Line Bank (Seoul, Korea). The cell lines were maintained in RPMI medium supplemented with $10 \%$ fetal bovine serum (FBS), $300 \mu \mathrm{g} / \mathrm{ml}$ L-glutamine, $100 \mathrm{U} / \mathrm{ml}$ penicillin and $0.1 \mathrm{mg} / \mathrm{ml}$ streptomycin in a humidified atmosphere of $95 \%$ air and $5 \% \mathrm{CO}_{2}$ at $37^{\circ} \mathrm{C}$.

\section{Construction of PTEN plasmids, transfections}

The PTEN plasmid was constructed as previously described (Hwang et al., 2001). The pcDNA3/PTEN plasmid was transfected to SNU-5 and SNU-216 cells using a calcium phosphate method (Promega, Madison, WI) according to the manufacturer's protocol. To obtain PTEN expressing cells, cells were cultured in $400 \mu \mathrm{g} / \mathrm{ml}$ G418 (Life Technologies, Grand Island, NY) for 2 weeks and three single colonies were selected using glass-cloning rings directly on plate and used for further chracteristics. Cells from clone \#1 of SNU-5 and clone \#3 of SNU216 were analyzed for their expression of PTEN by Western blot analysis.

\section{MTT assay}

Growth of SNU-5 (clone \#1) and SNU-216 (clone \#3) cells transfected with empty vector or wild-type PTEN and cell growth inhibition after the treatment of anticancer drugs was evaluated by MTT assay as previously described (Lee et al., 2002). In brief, SNU-5, SNU-216 cells carrying either the empty vector pcDNA3 or pcDNA3/PTEN were plated in $10 \%$ FBS-RPMI at a density of $1 \times 10^{5}$ cells/well in 12 -well plates until $60 \%$ confluency and changed to media for $12 \mathrm{~h}$, and then maintained in media in the presence of etoposide $(10 \mu \mathrm{M})$ or adriamycin (10 $\mu \mathrm{M})$. After the indicated periods of culture, $1 \mathrm{ml}(2$ $\mathrm{mg}$ ) of MTT solution was added to each well and incubated for $4 \mathrm{~h}$. Then, plates were centrifuged, and DMSO was added, and the plates were vigorously shaken to solubilize the MTT-formazan products. Absorbance at $540 \mathrm{~nm}$ was measured by spectrophotometer.

\section{Protein preparation and Western blot analysis}

Protein was extracted from cultured SNU-5 and SNU-216 cells transfected with empty vector $p c D N A 3$ or pcDNA3/PTEN using lysis buffer containing 150 $\mathrm{mM} \mathrm{NaCl}, 5 \mathrm{mM}$ EDTA, $50 \mathrm{mM}$ Tri-HCl $(\mathrm{pH} 8.0$ ), 1\%-NP 40, $1 \mathrm{mM}$ aprotinin, $0.1 \mathrm{mM}$ leupeptin, and 1 $\mathrm{mM}$ pepstatin and quantified based on the Bradford dye-binding procedure (Bio-Rad) as described previously (Hwang et al., 2001). Total proteins $(10 \mu \mathrm{g})$ were electrophoresed in $8 \%$ SDS-polyacrylamide gels under reducing conditions and electroblotted onto nitrocellulose membranes. The membranes were blocked using 5\% skim milk in PBS, and then incubated with the primary antibodies at 1:1,000 dilution for $2 \mathrm{~h}$. The proteins were visualized using the enhanced chemiluminescence (NEN, Boston, MA).

\section{RNA extraction and RT-PCR}

Total RNA was extracted from cultured SNU-5 and SNU-216 cells transfected with empty vector pcDNA3 or pcDNA3/PTEN using Trizol (Life Technologies) according to the manufacturer's instructions. Reverse transcription (RT) and agarose gel electrophoresis were performed as previously described (Lee et al., 2002). Primer sequences were: 1) IGF-I receptor sense, 5'-TTG CCC GAA GGT CTG TGA3'; antisense, 5'-CCC GTT GTT CCT GGT GTT-3'; 2) IGF-II sense, 5'-CGA TGC TGG TGC TTC TCA3'; antisense, 5'-GGG GTC TTG GGT GGG TAG-3'. In PCR amplification step, a standard cDNA for IGF-II, in which 113 base pairs had been removed from the IGF-II PCR product, was added and PCR amplification was carried out as described above. 


\section{Luciferase assay}

The -574 to +136 region of the IGF-II promoter, which was a generous gift from Dr. Charles Robert, Jr. (Dept. of Pediatrics, OHSU, Portland, Oregon) was recombined into the pGL2-basic vector (Promega). The pcDNA3/PTEN and IGF-II promoterpGL2-basic vectors were co-transfected into the SNU-5 cells using a calcium phosphate precipitation method (Promega). After $72 \mathrm{~h}$ transfection, the cells were washed with PBS and lysed using a reporter lysis buffer (Promega) according to the manufacturer's protocol. The luciferase activity was measured with a Lumat LB 96P luminometer (Berthold Systems, Aliquippa, PA).

\section{DNA fragmentation and nuclear condensation assay}

Cells transfected with the pcDNA3 or PTEN $\left(1 \times 10^{6}\right)$ were cultured in $150 \mathrm{~mm}$ culture dish until they reached $90 \%$ confluence and then treated with etoposide $(10 \mu \mathrm{M})$ for $24 \mathrm{~h}$. After the etoposide treatment, the cells were washed with cold PBS, and DNA fragmentation assay was performed as described previously ( $\mathrm{Yi}$ et al., 2002). For nuclear condensation assay, the pcDNA3 or PTEN-transfected cells were incubated in a 6 well plate with or without $10 \mu \mathrm{M}$ etoposide for $24 \mathrm{~h}$. After washing with PBS, cells were fixed with methyl alcohol/acetic acid, and stained with Hoechst 2495 solution (Sigma) as previously described (Yi et al., 2002).

\section{Statistical analysis}

The results are expressed as the mean \pm S.E. Statistical analysis of the data was performed using a Student's $t$ test, and $P$ values of $<0.05$ were considered significant.

\section{Results}

\section{Stable transfection of PTEN and growth of PTEN-transfected gastric cancer cells}

To characterize role of PTEN in gastric cancer, we stably overexpressed PTEN in SNU-5 and -216 gastric cancer cells. As shown in Figure 1, PTENtransfected SNU-5 and -216 cells produced high levels of $54 \mathrm{kDa}$ of PTEN protein, which showed only a weak signal in pcDNA3-transfected cells at 72
A

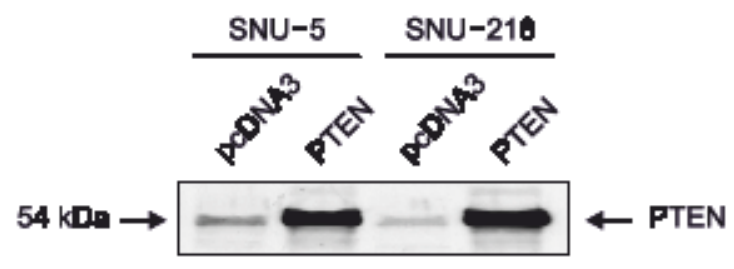

B $\quad \mathrm{SNU}-5$

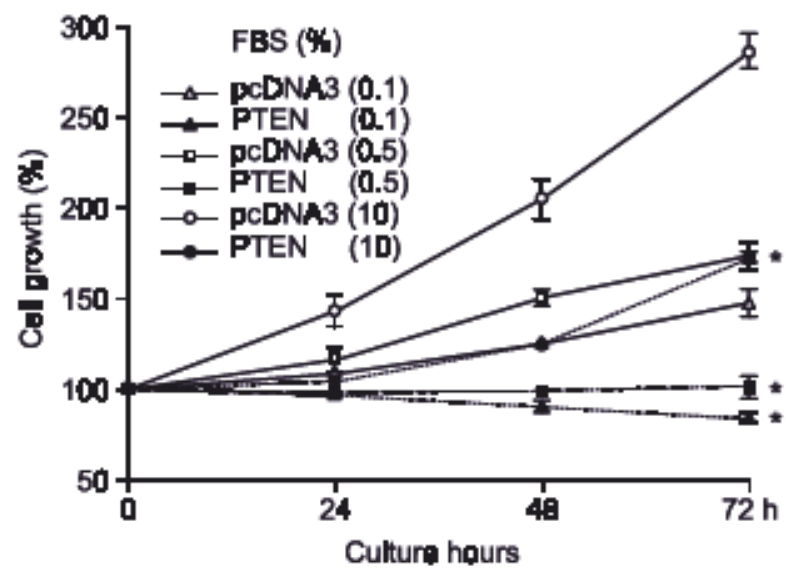

SNU-216

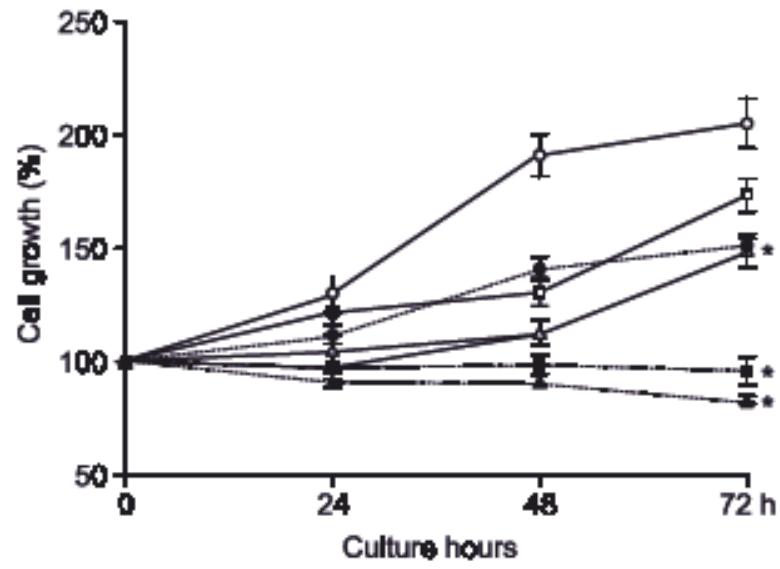

Figure 1. Expression of PTEN protein and effect of PTEN overexpression on cell growth. (A) Total proteins from the cell lysates of the stable SNU-5 and SNU-216 cells transfected with empty vector PCDNA3 or PTEN were extracted and subjected to immunoblotting as described in the Materials and Methods. (B) Stable cells transfected with the PCDNA3 or PTEN were seeded into 24 well plates at $1 \times 10^{5}$ cells per plate and were grown under various FBS concentration, over a $72 \mathrm{~h}$ period. At the indicated times, the number of vable cells was determined by a MTT assay and is presented as the percentage of cell growth. The results are a mean \pm S.E. of three separate experiments performed in duplicate wells. ${ }^{*} P<0.05$ compared with the pcDNA3-transfected cells. 
A

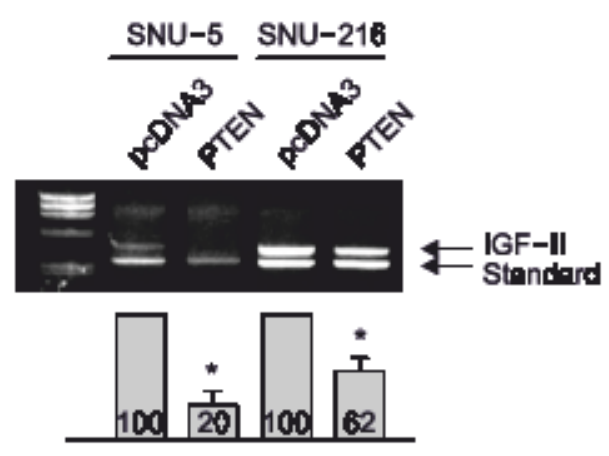

B
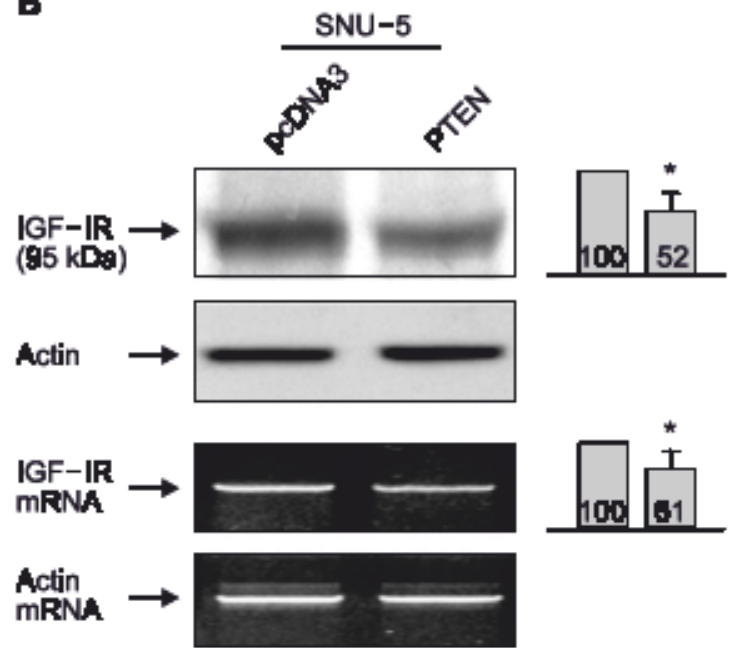

Figure 2. Effect of PTEN overexpression on IGF-II and IGF-I receptor expressions. Stable cells transfected with the pcDNA3 or PTEN were grown for 3 days. (A) Total RNA of each clone was extracted and anahyzed by compeftive-PCR, as described in the Materials and Methods. The bar graphs were generated from the densibmetric analysis of the IGF-IImRNA level from three separate experiments, and the results represent a mean $\pm S$ S.E. ${ }^{*} P<0.05$ compared with the $p c D N A 3$-transfected cells. (B) Total RNA and protein of each clone were extracted and anaIyzed by RT-PCR and immunobloting with anti-IGF-IR antibody. IGF-IR mRNA levels were normalized to the corresponding actin mRNA levels. ${ }^{*} P<0.05$ compared with the $P C D N A 3$-transfected cells.

h after transfection.

Because PTEN has been characterized as a tumor suppressor, this study examined the effect of PTEN overexpression on growth of the gastric cancer cells. Growth rate of the PTEN-overexpressing SNU-5 cells was considerably lower than that of the pcDNA3transfected cells with a maximum 2-fold reduction at $72 \mathrm{~h}$ after transfection regardless of FBS concentrations ranging from 0.1 to $10 \%$ (Figure $1 \mathrm{~B}, P<$ $0.05)$. The growth pattern of the PTEN-overexpressing SNU-216 cells was similar to that of the PTENoverexpressing SNU-5 cells. However, the growth inhibition of SNU-216 cells was more prominent in the low FBS concentration ( 0.1 and $0.5 \%$ ), com-

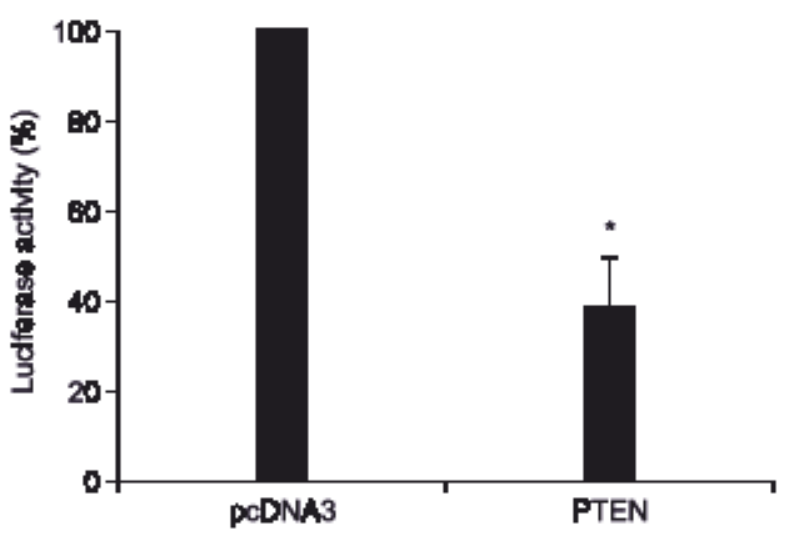

Figure 3. Effect of PTEN overexpression on IGF-II promoter activity. PCDNA3/PTEN and IGF-1/ promoter-pGL2-basic vectors were transiently cotransfected into the SNU-5 cells. Cell extracts were prepared after 72 $\mathrm{h}$ transfection and assayed for their luciferase activity as described in the Materials and Methods, and the results are presented as the percentage lucilerase activity. The results are presented as a mean $\pm S$.E. of three separate experiments performed in duplicate wells. ${ }^{*} P<0.05$ compared with the pcDNA3-transfected cells.

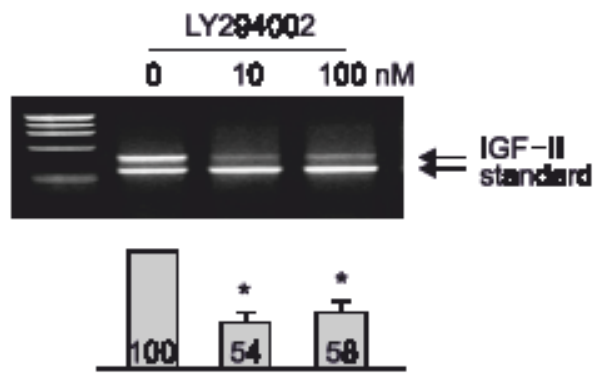

Figure 4. Effect of LY294002 on IGF-II expression. Stable SNU-5 Cells were grown until they were $90 \%$ confluent and incubated in the absence or presence of 10 or $100 \mathrm{nM}$ LY294002 for $24 \mathrm{~h}$. Total RNA was extracted and analyzed by competitive-PCR. The Bar graphs are generated from densibmetric analysis of the IGF-II mRNA levels from three separate experiments, and results represent the mean \pm S.E. ${ }^{*} P<0.05$ as compared with the cells without LY294002 treatment.

pared with the SNU-5 cells (Figure $2, P<0.05$ ).

\section{Downregulation of IGF-II and IGF-IR by PTEN}

Because IGFs play an important role in tumorigenesis and tumor progression in a variety of tumors and are potent mitogens in cancer cells, effects of PTEN on the expression of IGF-II and IGF-IR in gastric cancer cells were examined. As shown in Figure $2 \mathrm{~A}$ and $\mathrm{B}, I G F-\| I$ and IGF-IR were expressed in the pcDNA3-transfected SNU-5 and -216 cells. However, in the PTEN-overexpressing SNU-5 cells, IGF-II expression was significantly reduced by up to 5 -fold $(P<0.05)$. In addition, IGF-IR mRNA and 
protein expressions were significantly reduced by $P T E N$ overexpression in the SNU-5 cells (Figure 3B, $P<0.05$ ).

In order to address a molecular mechanism of PTEN activation in IGF-II expression, this study investigated whether PTEN activates the promoter of the IGF-II gene. The IGF-II promoter activity was decreased up to half after being transfected with $P T E N$, compared with that of the pcDNA3-transfected cells (Figure $3, P<0.05$ ). This result suggests that $P T E N$ overexpression induces a reduction in IGF-II expression at transcriptional level. Furthermore, there was a significant decrease in the IGF-II expression level as a result of a treatment with LY29002, PI3-kinase inhibitor (Figure 4, $P<0.05$ ). This result suggests that $P T E N$ downregulates IGF-II expression via Akt-mediated pathway in gastric cancer cells.

\section{Sensitization of cancer cells to anticancer drug by PTEN}

In order to examine whether growth inhibitory effect of anticancer drugs is enhanced by PTEN, this study investigated the antiproliferative effects of etoposide and adriamycin in PTEN-overexpressing SNU cells. Following a $10 \mu \mathrm{M}$ etoposide treatment for $72 \mathrm{~h}$, the growth of PTEN-overexpressing the SNU-5 cells was inhibited more than approximately 3 -fold compared with that of the pcDNA3-transfected cells (Figure 5, $P<0.05$ ). A similar growth inhibitory effect was observed with the $10 \mu \mathrm{M}$ adriamycin treatment $(P<0.05)$.

DNA fragmentation and nuclear condensation assays were performed to determine whether the

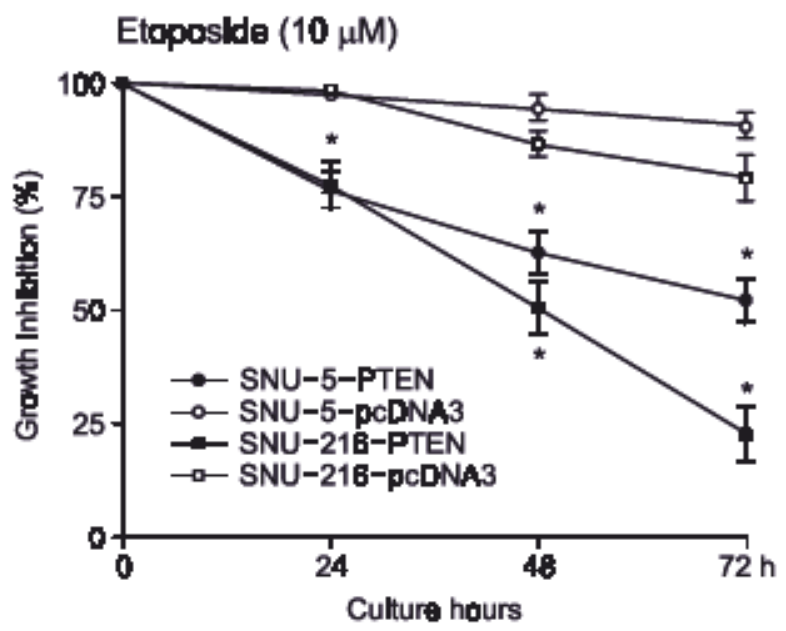

enhancement of cellular death in the PTEN-overexpressing gastric cancer cells was due to apoptosis. As shown in Figure $6 \mathrm{~A}$, treatment with $10 \mu \mathrm{M}$ etoposide for $24 \mathrm{~h}$ induced nucleosomal DNA fragmentation in the PTEN-overexpressing SNU cells but not in the pcDNA3-transfected cells. In addition, when the SNU- 5 cells were treated with $10 \mu \mathrm{M}$ etoposide for $24 \mathrm{~h}$, condensed and fragmented nuclei were observed in the PTEN-overexpressing SNU-5 cells only (Figure 6B, lower right panel). Overall, these results suggest that PTEN overexpression results in an increased sensitivity of SNU cells to anticancer drugs due to the enhancement of the apoptotic pathway.

\section{Discussion}

Gastric cancer is one of the leading causes of cancer death throughout the world, although its incidence has declined in many countries. The etiology of gastric cancer is still unclear. However, the remarkable technical advances in molecular biology seen in recent years have enhanced the understanding of carcinogenesis and the progression of cancer. Normal growth and differentiation of cells in the gastrointestinal tract are regulated by autocrine and paracrine secretion of peptide growth factors which are responsible for controlling maturation, differentiation and apoptosis (Moss, 1998; Park et al., 2005). In gastric cancer, where there is unrestricted growth, it is likely that there are abnormalities of secretion or response to those peptides. IGFs and their receptors may be important in the regulation of epithelial cell growth, but few data are available on

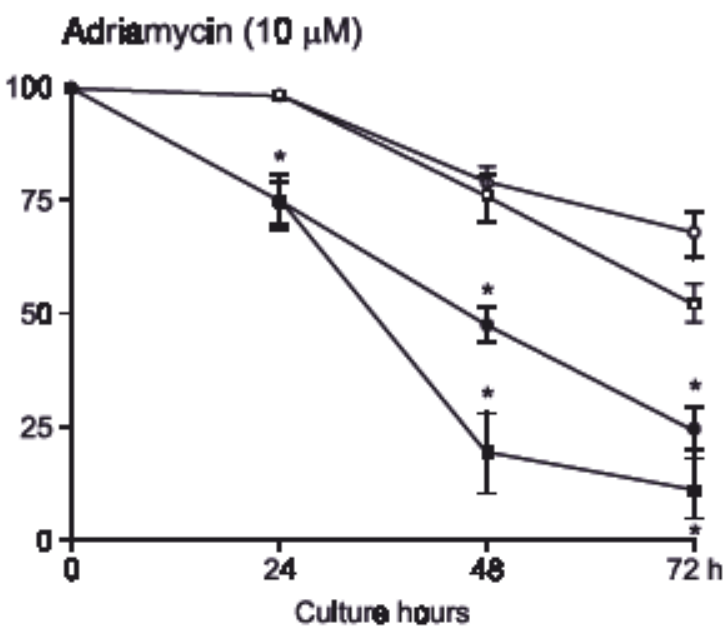

Figure 5. Effect of $P T E N$ overexpression on cellular sensitivity to anticancer drug. Stable cells transfected with the $p C D N A 3$ or $P T E N$ were grown until they reached $60 \%$ confluence, and were incubaled in the presence of $10 \mu \mathrm{M}$ etoposide or adriamycin over a $72 \mathrm{~h}$ period. After the indicated period of time, the level of growh inhibition was measured by a MTT assay, and is presented as the percentage of growth inhibition. The results are the mean $\pm S$.E. of three separate experiments performed in triplicate wells. ${ }^{*} P<0.05$ as compared with the $p c D N A 3$-transfected cells. 


\section{A}

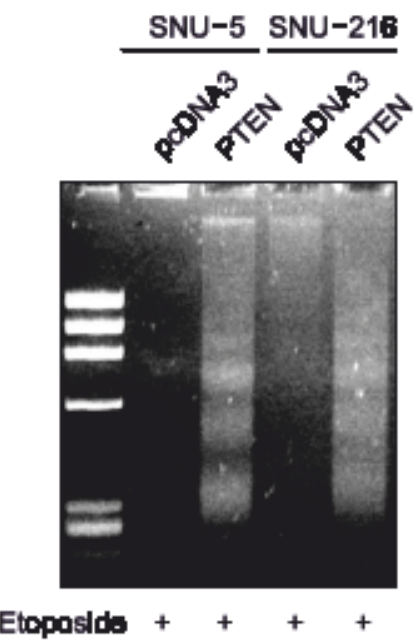

B

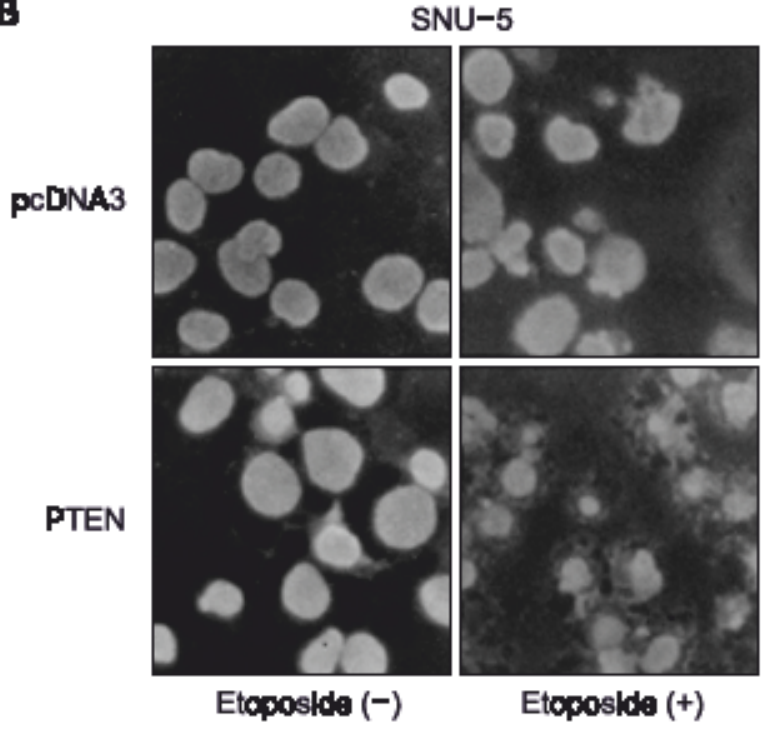

Figure 6. Effect of PTEN overxpression on apoplosis. The stable cells transfected with the pCDNA3 or PTEN were grown until they were $90 \%$ confluent and incubated in the presence or absence of $10 \mu \mathrm{M}$ etoposide for $24 \mathrm{~h}$. (A) DNA fragmentation assay: genomic DNA was extracted, separated on a $1.5 \%$ agarose gel, and stained with ethidium bromide, as described in Materials and Methods. A representative data of three separate experiments is shown. (B) Nuclear condensation assay. fixed cells on the slide were observed under a fluorescence microscope, as described in Materials and Methods.

the expression and biological function of the IGF system in gastric cancer. The IGF-II gene plays an important role in lymph vessel permeation especially in expanding-type gastric cancers (Shiraishi et al., 1998). Pavelic and colleagues (Pavdic et al., 2003) have reported that increased expression of IGF-II and IGF-IR genes is found in gastric cancer as compared with non-tumor tissue. Furthermore, there is a significant difference between IGF-II expression in the more aggressive diffuse type of gastric cancer than in the intestinal type.

In this study, we have found that overexpression of PTEN in a well-documented gastric cancer cell line inhibits cell growth and causes downregulation of IGF-II and IGF-IR expression. Furthermore, PTEN overexpression sensitizes these cells to the cytotoxic effect of anticancer drugs. PTEN is frequently deleted or mutated in a wide range of human tumors and tumor cell lines such as a glioblastoma, melanoma and gastric cancers, suggesting that PTEN plays important roles in tumorigenicity (Teng et al., 1997; Chang et al., 1999; Yi et al., 2001). It has previously been reported that PTEN inhibits cell growth in glioma and melanoma cells, and its major function is likely to be the phosphatase activity of PTEN that regulates the PI3 kinase/Akt pathway, which is a survival pathway (Li et al., 1988; Furnari et al., 1997). In this study, the results demonstrate that PTEN-overexpressing gastric cancer cells exhibits a lower proliferation rate than the $p c D N A 3$-transfected cells. This suggests that PTEN plays an important role in growth of gastric cancer cells.

Insulin-like growth factors, IGF-I and -II, are important mitogens in a number of different cell types (Daughaday et al., 1989). IGF-II, a mitogenic peptide necessary for normal fetal growth, is overexpressed in a number of malignant human tumors including gastric cancer (Wang et al., 1998; Yi et al., 2001). Consistent with the role of PTEN in the PI3/Akt signaling pathway, several lines of evidence suggest that PTEN regulates IGF-IGF-IR-induced Akt activity, thereby modulating IGF-mediated cell proliferative and antiapoptotic effects in a variety of cells (Davies et al., 1998; Stambolic et al., 1998). Recent studies have demonstrated that PTEN downregulates IGF-II and IGF-IR expression in hepatoma and prostate cancer cells, respectively, suggesting that antiproliferative effects of PTEN is, at least in part, mediated through the regulation of expression of components of the IGF system (Kang-Park et al., 2003; Zhao et al., 2004). Our reslts have shown that PTEN overexpression results in a marked reduction in IGF-II and IGF-IR expression in gastric cancer cells, and the downregulation of IGF-II is due to the transcriptional activation of its promoter. Furthermore, a PI3-kinase inhibitor also induces a marked decrease in IGF-II expression. These findings suggest that PTEN may regulate IGF-II expression via PKB/Aktdependent pathway in gastric cancer cells. By downregulating IGF-II and IGF-IR expression, PTEN reduces the IGF/IGF-IR-induced antiapoptotic signaling.

Variations in chemosensitivity of cells to different anticancer drugs is an important aspect of cancer research, and p53 and p21 have been shown to be 
the major determinants of cellular chemoresistance (Wahl et al., 1996; Waldman et al., 1996). Wu et al., $(2000)$ have reported that increased expression of PTEN renders the cells more sensitive to apoptotic cell death. In this study, we have observed that cell death caused by etoposide or adriamycin is significantly enhanced in the PTEN-overexpressing cells compared with the pcDNA3-transfected cells. In addition, it has also been found that the enhancement of cell death by PTEN expression is due to apoptosis. This finding suggests that tumor suppressive effect of PTEN is mediated, in part, by the enhanced sensitivity towards apoptotic cell death.

In summary, PTEN overexpression downregulates IGF-II and IGF-IR expression levels and sensitizes cancer cells to chemotherapy. This study suggests that PTEN suppresses cell growth by 1) inducing apoptosis mediated through the modulation of IGF system, and 2) sensitizing cancer cells to cell death by anticancer drugs toward apoptotic cell death.

\section{Acknowledgement}

This work was supported by from Korea Research Foundation Grant (KRF-2002-042-E00048).

\section{References}

Chang JG, Chen YJ, Perng LI, Wang NM, Kao MC, Yang TY, Chang CP, Tsai $\mathrm{CH}$. Mutation analysis of the PTEN/ MMAC1 gene in cancers of the digestive tract. Eur $\mathrm{J}$ Cancer 1999;35:647-51

Chen $\mathrm{H}$, Yan GC, Gishizky ML. Identification of structural characteristics that contribute to a difference in antiapoptotic function between human insulin and insulin-like growth factor-I receptors. Cell Grwoth Differen 1998;9:939-47

Daughaday WH, Rotwein P. Insulin-like growth factors I and II. Peptide, messenger ribonucleic acid and gene structure, serum and tissue concentrations. Endocr Rev 1989;10:68-91

Davies MA, Lu Y, Sano T, Fang X, Tang P, LaPushin R, Koul D, Bookstein R, Stokoe D, Yung WK, Mills GB, Steck PA. Adenovirus transgene expression of MMAC/PTEN in glioma cells inhibits Akt activation and induces anoikis. Cancer Res 1998;58:5285-90

Furnari FB, Lin H, Huang HS, Cavenee WK. Growth suppression of glioma cells by PTEN requires a functional phosphatase catalytic domain. Proc Natl Acad Sci USA 1997; $94: 12479-84$

Hemmings BA. Akt signaling: Linking membrane events to Iffe and death dedsions. Sdience 1997;275:628-30

Hwang PH, Yi HK, Kim DS, Nam SY, Kim JS, Lee DY. Suppression of tumorigenidty and metastasis in B16F10 cells by PTEN/MMAC1/TEP1 gene. Cancer Lett 2001;172: 83-91

KangPark S, Lee Y, Lee Y. PTEN modulates insulin-like growth factor II (IGF-II)-mediated signaling; the protein phosphatase activity of PTEN downregulates IGF-II expression in hepatoma cells. FEBS Lett 2003;545:203-8

Lee DY, Yi KH, Hwang PH, Oh Y. Enhanced expression of insulin-like growth factor binding protein-3 sensitizes the growth inhibitory effect of anticancer drugs in gastric cancer cells. Biochem Biophys Res Commun 2002;294:480-6

LeRoith D, Werner H, Beitner-Johnson D, Roberts CT Jr. Molecular and cellular aspects of the insulin-like growth factor I receptor. Endocr Rev 1995;16:143-63

Li DM, Sun H. PTEN/MMAC1/TEP1 suppresses the tumorigenidity and induces G1 cell cycle arrest in human glioblastoma cells. Proc Natl Acad Sci USA 1988;95:15406-11

Llaw D, Marsh DJ, Li J, Dahia PLM, Wang SI, Zheng Z, Bose S, Call KM, Tsou HC, Peacocke M, Eng C, Parsons R. Germline mutations of the PTEN gene in Cowden disease, an inherited breast and thyroid cancer syndrome. Nat Genet 1997; 16:64-6

Macaulay VM. Insulin-like growth factors and cancer. $\mathrm{Br} \mathrm{J}$ Cancer 1992;65:311-20

Maehama T, Dixon JE. The tumor suppressor, PTEN/ MMAC1, dephosphorylates the lipid second messenger, phosphatidylinositol 3,4,5-triphosphate. J Biol Chem 1998; 273:13375-8

Moss SF. Cellular markers in the precancerous process. Aliment Phamacol Ther 1998;12(suppl. 1):91-109

Park M, Park H, Kim WH, Cho H, Lee JH. Presence of autocrine hepatocyte growth factor-Met signaling and its role in proliferation and migration of SNU-484 gastric cancer cell line. Exp Mol Med 2005;37:213-9

Pavelic K, Kolak T, Kapitanovic S, Radosevic S, Spaventi S, Kruslin B, Pavelic J. Gastric cancer: the role of insulin-like growth factor 2 (IGF 2) and its receptors (IGF 1R and M6-PI IGF 2R). J Pathol 2003;201:430-8

Shiraishi T, Mori M, Yamagata $M$, Haraguchi $M$, Ueo $H$, Sugimachi $K$. Expression of insulin-like growth factor 2 mRNA in human gastric cancer. Int J Oncol 1998;13:519-23

Stambolic V, Suzuki A, de la Pomapa JL, Brothers GM, Mirtos C, Sasaki T, Ruland J, Penninger JM, Sidervski DP, Mark TW. Negative regulation of PKB/Akt-dependent cell survival by the tumor suppressor PTEN. Cell 1998;95:29-39

Steck PA, Lin H, Langford LA, Jasser SA, Koul D, Young WK, Pershouse MA. Functional and molecular analyses of $10 \mathrm{q}$ deletions in human gliomas. Genes Chromosomes Cancer 1999;24:135-43

Sung YH, Hwang SY, Farooq M, Kim JC, Kim MK. Growth promotion of HepG2 hepatoma cells by antisense-mediated knockdown of glypican-3 is independent of insulin-like growth factor 2 signaling. Exp Mol Med 2003;35:257-62

Teng DH, Hu R, Lin H, Davis T, Frye C, Swedlund B, Hansen KL, Vinson VL, Gumpper KL, Ellis A, E-Naggar A, Frazier M, Jasser S, Langford LA, Lee J, MillsGB, Pershous MA, Wahl AF, Donaldson KL, Fairchild C, Lee FY, Foster SA, Demers GW, Galloway DA. Loss of normal p53 function confers sensitization to Taxol by increasing G2/M arrest and 
apoptosis. Nat Med 1996;2:72-9

Wahl AF, Donaldson KL, Fairchild C, Lee FY, Foster SA, Deemers GW, Galloway DA. Loss of normal p53 function confers sensitization to Taxol by increasing G2/M arrest and apoptosis. Nat Med 1996;2:72-9

Waldman T, Lengauer C, Kinzler KW, Vogelstein B. Uncoupling of $S$ phase and mitosis induced by anticancer agents in cells lacking p21. Nature 1996;381:713-6

Wang W, Kumar P, Epstein J, Helman L, Moore JV, Kumar $S$. Insulin-like growth factor II and PAX3-FKHR cooperate in the oncogenesis of inabdomyosarcoma. Cancer Res 1998; 58:4426-33

Wu RC, Li X, Schonthal AH. Transcriptional activation of
p21WAF1 by PTEN/MMAC1 tumor suppressor. Mol Cell Biochem 2000;203:59-71

Yi HK, Hwang PH, Yang DH, Kang CW, Lee DY. Expression of insulin-like growth factors (IGFs) and the IGF-binding proteins (IGFBPs) in human gastric cancer cells. Eur $J$ Cancer 2001;37:2257-63

Yi HK, Nam SY, Kim JS, Kim JS, Lee DY, Hwang PH. Induction of apoptosis in $\mathrm{K} 562$ cells by dominant negative c-myb. Exp Hematol 2002;30:1139-46

Zhao H, Dupont J, Yakar S, Karas M, LeRoith D. PTEN inhibits cell proliferation and induces apoptosis by downregulating cell surface IGF-IR expression in prostate cancer cells. Oncogene 2004;23:786-94 